Check for updates

Cite this: RSC Adv., 2018, 8, 31231

Received 21st July 2018

Accepted 23rd August 2018

DOI: $10.1039 / \mathrm{c} 8 \mathrm{ra06178e}$

rsc.li/rsc-advances

\title{
AIE-active polyanetholesulfonic acid sodium salts with room-temperature phosphorescence characteristics for $\mathrm{Fe}^{3+}$ detection $\dagger$
}

\author{
Xiaojin Qin, ${ }^{a}$ Shiqi Wang, ${ }^{a}$ Lian Luo, ${ }^{b}$ Gang He, ${ }^{a}$ Huazhen Sun, ${ }^{a}$ Yongyang Gong, (DD *a
} Bingli Jiang ${ }^{\star b}$ and Chun Wei ${ }^{\star a}$

\begin{abstract}
Room-temperature phosphorescent materials have been a major focus of research and development during the past decades, due to their applications in OLEDs, photovoltaic cells, chemical sensors, and bioimaging. However, achieving polymeric phosphorescent materials without heavy-metal atoms and halogens under ambient conditions remains a major challenge. Here, we report a polymeric phosphor, namely polyanetholesulfonic acid sodium salt, which not only has room temperature phosphorescence characteristic but also aggregation-induced emission and dependence on the excitation wavelength characteristics. Moreover, it can recognize $\mathrm{Fe}^{3+}$ effectively.
\end{abstract}

\section{Introduction}

Polymeric luminophores are promising materials for applications in various areas such as light-emitting diodes, plastic lasers, solar cells, chemosensors and bioprobes. ${ }^{1-7}$ In response to the growing demand, a large number of polymeric luminescent materials have been synthesized. However, many of them are highly radiative in dilute solutions while being weakly luminescent or quenched in concentrated solutions or in the solid state, exhibiting concentration quenching and aggregation-caused quenching (ACQ) problems. $^{8}$ The ACQ effect has limited the scope of technological applications because luminescent materials have to be used in the solid state (e.g. as thin films), where the luminophores tend to form aggregates. ${ }^{9}$ To alleviate the ACQ effect in the condensed phase, various chemical, physical and engineering approaches have been developed. For example, branched chains, spiro kinks, and dendritic wedges have been covalently attached to aromatic rings to impede aggregate formation. However, those attempts have met with limited success. ${ }^{9}$

Aggregation-induced emission (AIE) characteristic, which is opposite to the ACQ effect was discovered by Tang et al. in 2001. Since then, many organic and polymeric AIE-active materials have been synthesized and applied in various fields. ${ }^{\mathbf{1 0}}$ However,

${ }^{a}$ Key Laboratory of New Processing Technology for Non-ferrous Metals and Materials, Ministry of Education, College of Materials Science and Engineering, Guilin University of Technology, Guilin 541004, China.E-mail: yygong@glut.edu.cn; 1986024@glut. edu.cn

${ }^{b}$ College of Pharmacy, Guilin Medical University, Guilin 541004, China. E-mail: jiangbingli@foxmail.com

$\dagger$ Electronic supplementary information (ESI) available: UV spectra, XRD and the mean diameter. See DOI: 10.1039/c8ra06178e in the field of polymeric AIE-active materials, most studies focus on fluorescent polymeric materials, ${ }^{\mathbf{1 1 - 1 3}}$ few literature examples deal with phosphorescent polymers at ambient or cryogenic temperatures. ${ }^{\mathbf{1 4 - 1 7}}$

Polymeric room temperature phosphorescent (RTP) materials have attracted a great deal of interest due to their potential applications in organic light-emitting diodes (OLED),${ }^{18}$ photovoltaics, ${ }^{19}$ photocatalytic reactions, ${ }^{20}$ and bioimaging. ${ }^{21}$ Phosphorescent compounds have a large Stokes shift and long lifetimes. ${ }^{22}$ Therefore, for applications in bioprobes, phosphorescent probes can distinguish the background signals from each other by using time-resolved techniques, thus improving the signal-to-noise and sensitivity of detection. ${ }^{23}$ Large numbers of polymeric RTP materials that have been developed so far are rare metal complexes involving Ir and Pt. However, these compounds have potential toxicity and instability in aqueous environments. And these noble metals are not only costly but also resource-limited, which have hindered the development of phosphorescent materials. Also, most organic RTP materials that have been reported are compounds containing halogen atoms, which are essential units to facilitate intersystem crossing: ${ }^{24-27}$ However, aromatic halogen-containing compounds may have adverse effects on the environment and human health. ${ }^{28-30}$ Therefore, polymeric luminophores without noble metals and halogens might be better choices.

Herein, a noble metal- and halogen-free polymer material (Scheme 1) based on commercial polyanetholesulfonic acid sodium salts (PASAS, CAS number: 52993-95-0) is purified and further studied. The results show that PASAS is AIE active, and the photoluminescence quantum yield (PLQY) of its solid samples $\left(\Phi_{\text {solid }}\right)$ is $7.57 \%$. More importantly, PASAS also exhibits RTP, and the phosphorescence lifetimes at 460 and $525 \mathrm{~nm}$ are 


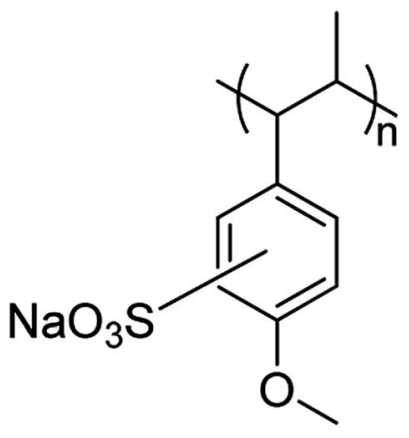

Scheme 1 Chemical structure of polyanetholesulfonic acid sodium salts.

$0.24 \mathrm{~ms}$ and $0.77 \mathrm{~ms}$, respectively. In addition, it can also recognize $\mathrm{Fe}^{3+}$ effectively in aqueous solution.

\section{Experimental}

\subsection{Materials}

PASAS was obtained from J\&K Scientific., Ltd. Metal salts of $\mathrm{LiCl}, \mathrm{CuCl}, \mathrm{AgNO}_{3}, \mathrm{CaCl}_{2}, \mathrm{MgSO}_{4}, \mathrm{AlCl}_{3} \cdot 6 \mathrm{H}_{2} \mathrm{O}, \mathrm{CuNO}_{3} \cdot 3 \mathrm{H}_{2} \mathrm{O}$, $\mathrm{FeCl}_{2} \cdot 4 \mathrm{H}_{2} \mathrm{O}, \mathrm{FeCl}_{3} \cdot 6 \mathrm{H}_{2} \mathrm{O}, \mathrm{ZnNO}_{3} \cdot 6 \mathrm{H}_{2} \mathrm{O}$ were obtained from Xilong Chemical Co., Ltd. $\mathrm{CoCl}_{2} \cdot 6 \mathrm{H}_{2} \mathrm{O}, \mathrm{K}_{2} \mathrm{CO}_{3}, \mathrm{CdCl}_{2} \cdot 5 / 2 \mathrm{H}_{2} \mathrm{O}$ and $\mathrm{NiCl}_{2} \cdot 6 \mathrm{H}_{2} \mathrm{O}$ were obtained from Adamas Reagent Co., Ltd. Distilled water was prepared by Milli-Q Pure Water instrument. The commercially available reagents were used without further purification.

\subsection{Characterization}

UV-vis absorption spectra were obtained using a UV3600 UV-vis spectrophotometer under ambient conditions. Fluorescence spectra of the solutions were obtained from a Cary Eclipse fluorescence spectrophotometer. The mean diameter $\left(D_{\mathrm{m}}\right)$ and polydispersity (PD) of PASAS solution were determined on a Malvern Zetasizer nano ZS90 instrument equipped with a HeNe laser $(\lambda=633 \mathrm{~nm})$ at a scattering angle of $90^{\circ}$ at $25^{\circ} \mathrm{C}$. X-ray diffraction (XRD) measurements were performed on a $\mathrm{X}^{\prime}$ Pert PRO X-ray diffractometer. The fluorescence lifetimes were measured with an FLS-980 fluorescence spectrophotometer. The emission spectra, quantum yields and phosphorescence lifetime of solid samples were recorded on a FluoroMax-4 fluorescence spectrophotometer. Quantum yields $(\Phi)$ of PASAS in water as solvent were estimated using 2-aminopyridine $(\Phi=$ $60 \%$ in $0.1 \mathrm{~N} \mathrm{H}_{2} \mathrm{SO}_{4}$ ) as standard. ${ }^{31}$ Centrifugation was carried out with CT14D high-speed table centrifuge.

\subsection{Purification of PASAS}

First, a PASAS solution was obtained by dissolving it in a small amount of water. Then, a straw-stuffed with a small amount of cotton at the tip was used for sucking the solution into a beaker filled with a large amount of methanol, so that the solid samples of PASAS could slowly precipitate. At last, the pure solid samples of PASAS were obtained by centrifugation and drying.

\subsection{Preparation of selectivity towards $\mathrm{Fe}^{3+}$}

Solutions of the following metal ions $\left(\mathrm{Li}^{+}, \mathrm{K}^{+}, \mathrm{Ag}^{+}, \mathrm{Cu}^{+}, \mathrm{Ca}^{2+}\right.$, $\mathrm{Mg}^{2+}, \mathrm{Zn}^{2+}, \mathrm{Cd}^{2+}, \mathrm{Co}^{2+}, \mathrm{Ni}^{2+}, \mathrm{Cu}^{2+}, \mathrm{Fe}^{2+}, \mathrm{Fe}^{3+}$, and $\mathrm{Al}^{3+}, 2.0 \times$ $\left.10^{-3} \mathrm{~mol} \mathrm{~L}^{-1}\right)$ were prepared in distilled water. A stock solution of PASAS $\left(5.0 \mathrm{mg} \mathrm{mL}^{-1}\right)$ was prepared with distilled water. The resulting solutions were obtained by mixing the metal ion solutions $(2 \mathrm{~mL})$ with the polymer solutions $(5 \mathrm{~mL})$, respectively. Then the absorption and fluorescence measurements of the mixed solutions were conducted.

\subsection{Preparation of fluorescence assay for detecting $\mathrm{Fe}^{3+}$}

Solutions of $\mathrm{Fe}^{3+}$ with different concentrations $\left(0,0.02 \times 10^{-3}\right.$, $0.04 \times 10^{-3}, 0.06 \times 10^{-3}, 0.08 \times 10^{-3}, 0.1 \times 10^{-3}, 0.2 \times 10^{-3}$, $0.4 \times 10^{-3}, 0.8 \times 10^{-3}, 1.2 \times 10^{-3}, 1.6 \times 10^{-3}, 2.0 \times$ $10^{-3} \mathrm{~mol} \mathrm{~L}^{-1}$ ) were prepared with distilled water. The stock solution of PASAS $\left(5.0 \mathrm{mg} \mathrm{mL^{-1 }}\right)$ was prepared with distilled water at room temperature. The resulting solutions were obtained by mixing the $\mathrm{Fe}^{3+}$ solutions $(2 \mathrm{~mL})$ with polymer solutions $(5 \mathrm{~mL})$. Then the absorption and fluorescence measurements of the mixed solutions were conducted.

\section{Results and discussion}

\subsection{Excitation dependent fluorescence emission}

Photoluminescence properties of many polymer materials have a dependence on the excitation wavelengths because of the dispersity of their molecular weight. ${ }^{32-34}$ To verify whether it had a dependence on excitation wavelengths, the fluorescence emission spectra of PASAS aqueous solution $\left(10 \mathrm{mg} \mathrm{mL}^{-1}\right)$ were measured at different excitation wavelengths. As shown in Fig. 1a, when excited at $310 \mathrm{~nm}$, it showed a maximal emission at $372 \mathrm{~nm}$. With increasing excitation wavelengths, the emission intensity tended to increase first and then decrease, meanwhile the emission wavelength gradually redshifted. When excited at $320 \mathrm{~nm}$, the fluorescence intensity was the strongest. At the same time, we could also observe that the illuminant colors were deep blue and sky blue under $312 \mathrm{~nm}$ and $365 \mathrm{~nm}$ UV radiation, respectively. To compare the optical behavior of different emissions, we measured the time-resolved photoluminescent (PL) decay curves, as shown in Fig. 1b. The fluorescence lifetimes at $372 \mathrm{~nm}$ and $420 \mathrm{~nm}$ were $27.97 \mathrm{~ns}$ and $4.31 \mathrm{~ns}$, respectively. These results indicated PASAS had versatile optical properties.

\subsection{Aggregation-induced emission (AIE) characteristics}

In order to find out whether it had AIE characteristics, fluorescence spectra and UV absorption spectra of PASAS aqueous solutions with different concentrations were measured. As shown in Fig. S1a (ESI $\dagger$ ), the absorption intensity gradually increased and the absorption wavelength gradually red-shifted as the concentration gradually increased. Meanwhile, the absorption spectra also showed the end tailing phenomenon. These phenomena could be due to the scattering effect caused by the accumulation of aggregated particles in the system. As shown in Fig. 2b, when the concentration was $0.1 \mathrm{mg} \mathrm{mL}^{-1}$, the emission intensity was very weak. The emission intensity 

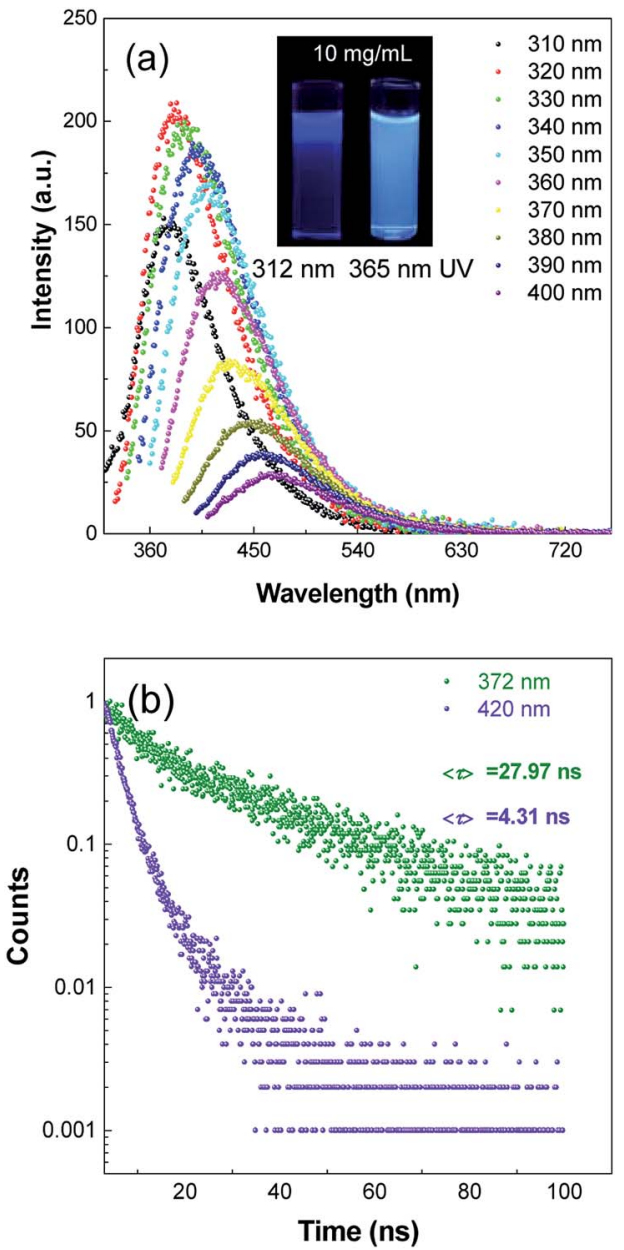

Fig. 1 (a) Fluorescence spectra of PASAS aqueous solution $(10 \mathrm{mg}$ $\mathrm{mL}^{-1}$ ) with different excitation wavelengths. (b) The effect of excitation wavelength on fluorescence lifetime of PASAS aqueous solution (10 $\mathrm{mg} \mathrm{mL}^{-1}$ ).

continuously strengthened with the increase in concentration. When increased to $10 \mathrm{mg} \mathrm{mL}^{-1}\left(D_{\mathrm{m}}=185 \mathrm{~nm}, \mathrm{PD}=0.48\right.$, Fig. S1b, ESI $\dagger$ ), the emission intensity rapidly increased due to molecular aggregation, giving a strong blue emission at about $380 \mathrm{~nm}$. Meanwhile, it could also be seen that the luminescence intensity increased with the increase in concentration under $365 \mathrm{~nm}$ UV radiation (Fig. 2a), which indicated aggregationinduced emission (AIE) characteristics.

To gain more information on the AIE process, emission spectra of PASAS aqueous solution and ACN/water mixtures were measured (Fig. S2a†). ACN was adopted because it was a nonsolvent for PASAS, the polymer chains may be aggregated in the mixture with high ACN fractions. When the ACN fraction $\left(f_{\mathrm{ACN}}\right)$ was $0 \%$, only a weak signal was recorded. However, when $f_{\mathrm{ACN}}$ was increased to $99 \%\left(D_{\mathrm{m}}=116.2 \mathrm{~nm}, \mathrm{PD}=0.37\right.$, Fig. S2b, ESI $\dagger$ ), the emission intensity rapidly increased. This also indicated that aggregates formed with the increase in the nonsolvent content. Besides, the $\Phi_{\text {solution }}$ values of PASAS aqueous solution were as low as $1.70 \%$. However, the $\Phi_{\text {solid }}$ values of PASAS solids increased to $7.57 \%$, and those results also suggest that PASAS is AIE active.

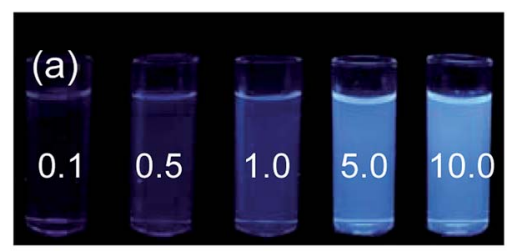

365 nm UV

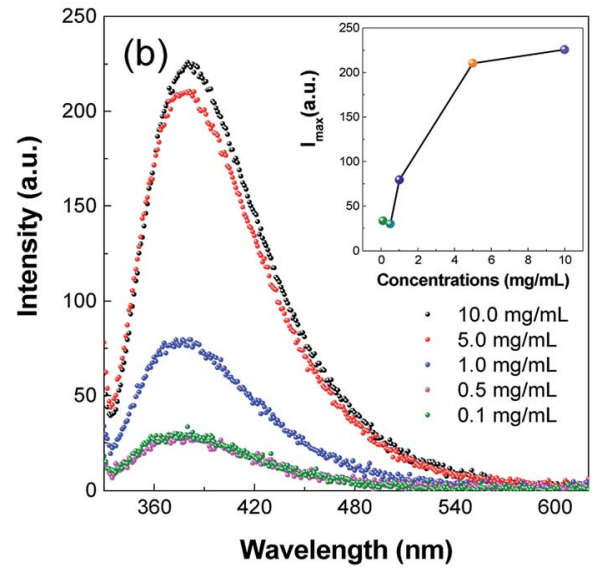

Fig. 2 (a) Photographs taken under $365 \mathrm{~nm}$ UV light and (b) fluorescence spectra of PASAS aqueous solutions with different concentrations.

\subsection{Room temperature phosphorescence (RTP) characteristics}

Preliminary studies found PASAS solids could emit light blue luminescence with excitation by a UV lamp at $365 \mathrm{~nm}$ under ambient conditions (Fig. 3a). To gain deeper insight into the nature of the light blue emission, the prompt and steady-state photoluminescence spectra of solid samples were collected under ambient conditions. As shown in Fig. 3b, the fluorescence emission wavelength gradually red-shifted with an increase in the excitation wavelength, which also indicated a dependence on the excitation wavelength. Time-resolved (delayed) PL spectra were obtained $0.5 \mathrm{~ms}$ after excitation (Fig. 3c). The delayed spectra were found to exhibit dual emission bands peaking at around 460 and $525 \mathrm{~nm}$. Furthermore, the difference between the peak positions of the prompt spectrum and the delayed spectrum was nearly $80 \mathrm{~nm}$ under excitation of $320 \mathrm{~nm}$, which indicated that it was room temperature phosphorescence rather than delayed fluorescence. To further confirm PASAS solids had room temperature phosphorescence characteristics, time-resolved decay curves at 460 and $525 \mathrm{~nm}$ were recorded (Fig. 3d). The results showed that the lifetimes of both were in milliseconds, which accorded with the phosphorescence characteristic of the long lifetime. Therefore, the above results showed that PASAS solids had RTP characteristics. ${ }^{35}$ RTP was ascribed to restricted molecular motions (RMM) ${ }^{36}$ from the strong ionic bond and abundant hydrogen bonding in the crystalline state (Fig. S3, ESI $\dagger$ ). Such intermolecular and intramolecular interactions greatly rigidified the molecular conformation and drastically decreased the nonradiative deactivation channels of the triplet excitons, thus giving rise to phosphorescent emission at room temperature. ${ }^{36,37}$ 


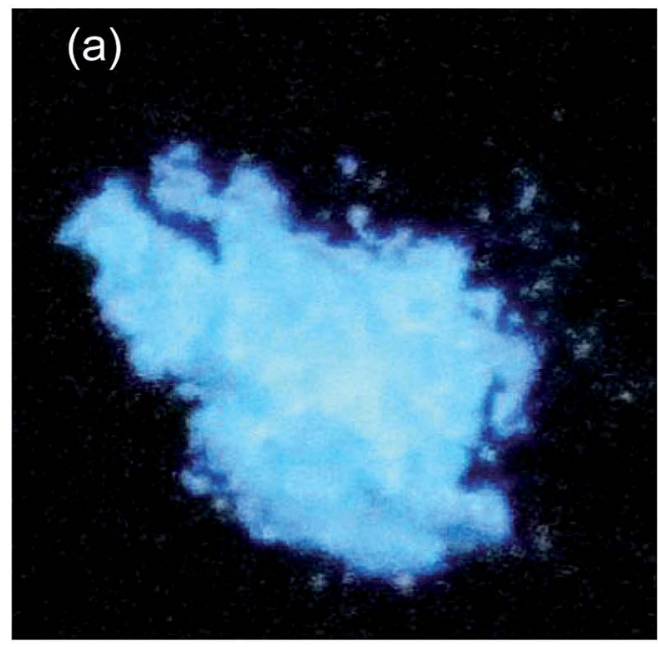

365nm UV

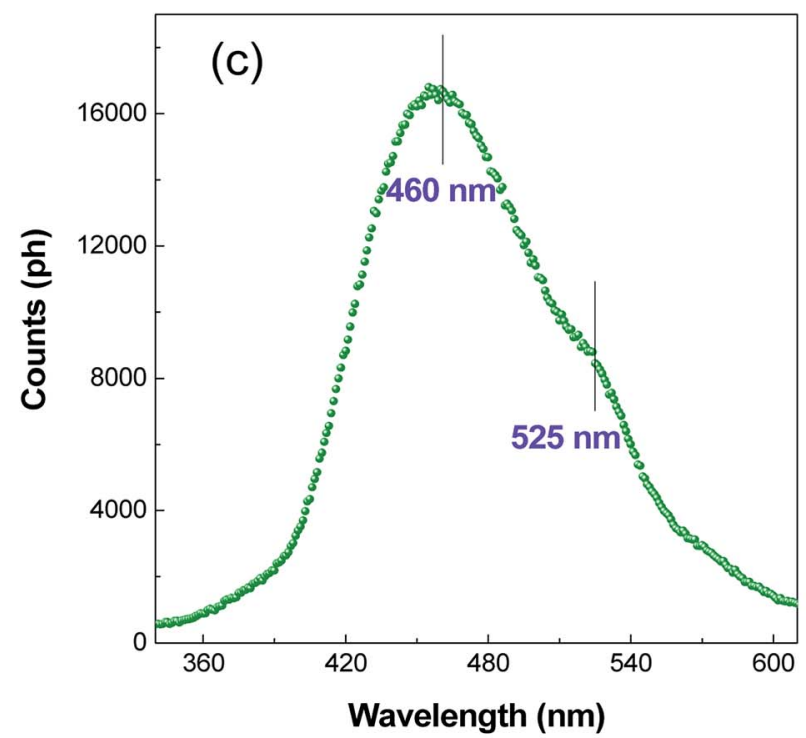

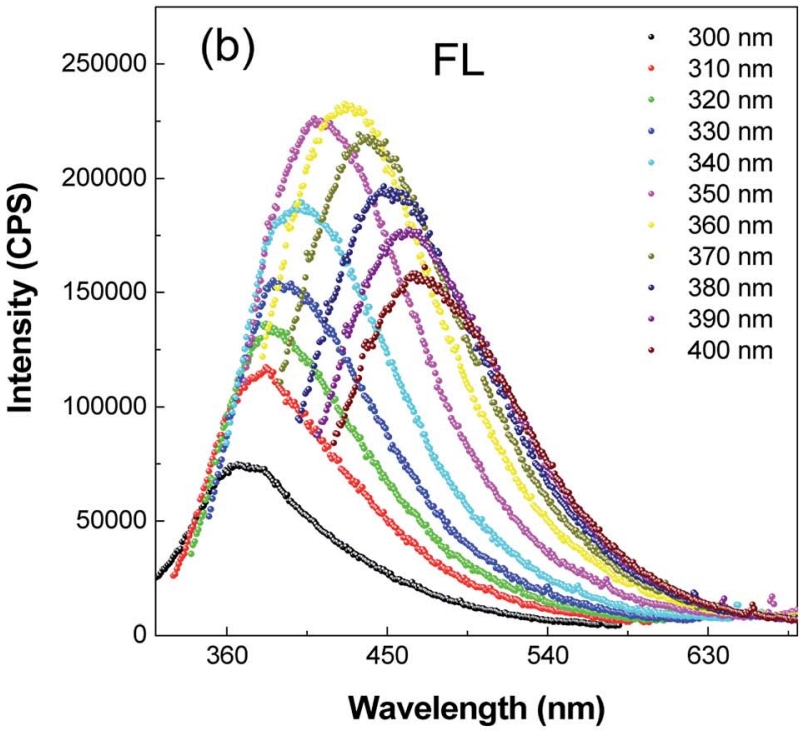

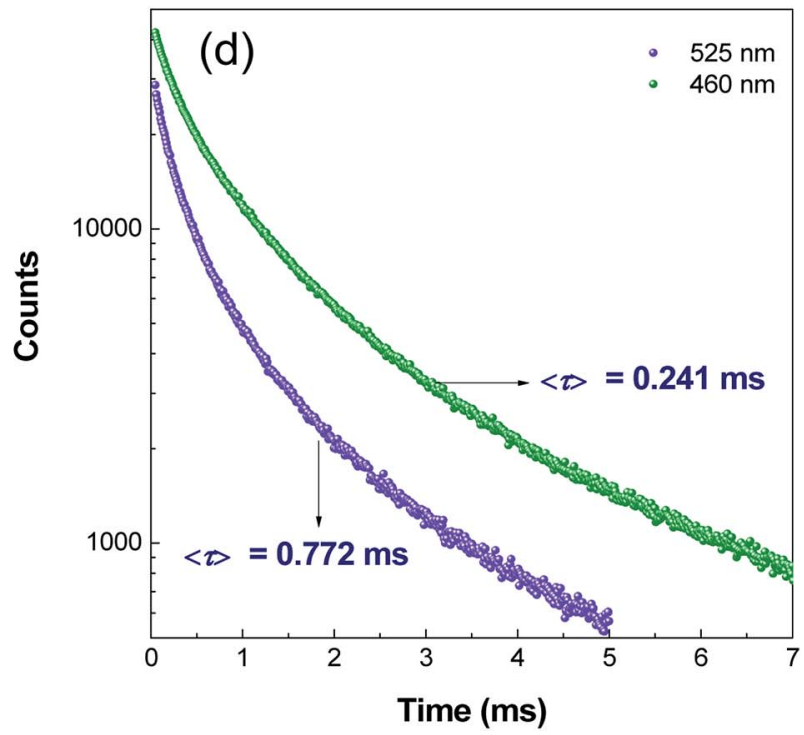

Fig. 3 (a) The photograph of PASAS solids taken under $365 \mathrm{~nm}$ UV radiation. (b) and (c) are the fluorescence and phosphorescence spectra of PASAS solids, respectively. (d) Time-resolved decay curves of PASAS solids at 460 and $525 \mathrm{~nm}$. Excitation wavelength and delay time of phosphorescence spectra are $320 \mathrm{~nm}$ and $0.5 \mathrm{~ms}$, respectively.

\subsection{Selectivity of polymer chemosensor towards $\mathrm{Fe}^{3+}$}

The UV absorption and fluorescence response of PASAS $(5 \mathrm{mg}$ $\mathrm{mL}^{-1}$ ) to various metal ions including $\mathrm{Li}^{+}, \mathrm{K}^{+}, \mathrm{Ag}^{+}, \mathrm{Mg}^{2+}, \mathrm{Ca}^{2+}$, $\mathrm{Zn}^{2+}, \mathrm{Cd}^{2+}, \mathrm{Cu}^{+}, \mathrm{Cu}^{2+}, \mathrm{Co}^{2+}, \mathrm{Ni}^{2+}, \mathrm{Fe}^{2+}, \mathrm{Fe}^{3+}$ and $\mathrm{Al}^{3+}(2 \times$ $\left.10^{-3} \mathrm{~mol} \mathrm{~L}^{-1}\right)$ were studied in aqueous solution $(5: 2, \mathrm{v} / \mathrm{v})$. $365 \mathrm{~nm}$ UV photographs had preliminarily indicated that only $\mathrm{Fe}^{3+}$ could quench the luminescence of the solution (Fig. 4a). Meanwhile, only $\mathrm{Fe}^{3+}$ could enhance the absorption intensity, which changed a little after addition of other metal ions (Fig. S4, ESI $\dagger$ ). Interestingly, when $2 \mathrm{~mL}$ of different metal ions were added, only the addition of $\mathrm{Fe}^{3+}$ significantly quenched the fluorescence intensity of PASAS at $380 \mathrm{~nm}$ (Fig. 4b). Other metal ions could not induce a significant change in fluorescence intensity of PASAS. To gain a deeper insight into the mechanism of fluorescence quenching, the fluorescence lifetimes before and after the addition of $\mathrm{Fe}^{3+}\left(0.2 \times 10^{-3} \mathrm{~mol} \mathrm{~L}^{-1}\right)$ were measured. Here, the lifetime values of PASAS solution before and after the addition of $\mathrm{Fe}^{3+}$ ion are determined as 11.2 and 8.6 ns (Fig. S5, ESI $\dagger$ ), respectively. The results show that the lifetime becomes shorter after the addition of $\mathrm{Fe}^{3+}$. Thus, the reason of fluorescence emission quenching was the stronger coordination ability to the polymer sensor and photoinduced electron transfer (PET) process $^{38,39}$ from sodium benzene sulfonic acid moiety to the coordinated metal ions $\left(\mathrm{Fe}^{3+}\right)$. Therefore, $\mathrm{Fe}^{3+}$ could be rapidly distinguished from other metal ions by comparing the luminescence intensity of the solution. It also indicated that PASAS was a highly selective fluorescence probe for $\mathrm{Fe}^{3+}$ among various metal ions.

\subsection{Fluorescence assay for detecting $\mathrm{Fe}^{3+}$}

To evaluate the $\mathrm{Fe}^{3+}$ sensing property of PASAS, the UV absorption and fluorescence response of PASAS $\left(5 \mathrm{mg} \mathrm{mL}^{-1}\right)$ in 

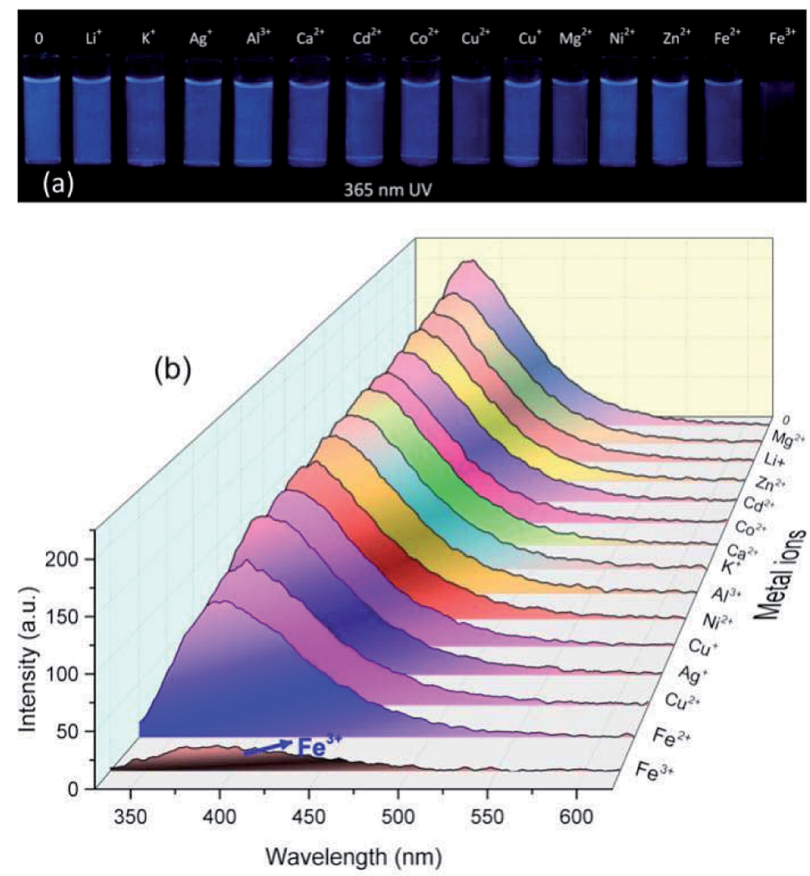

Fig. 4 (a) Photographs taken under 365 nm UV light and (b) fluorescence spectra of PASAS aqueous solution $\left(5 \mathrm{mg} \mathrm{mL}^{-1}\right)$ in the presence of various metal ions $\left(2 \times 10^{-3} \mathrm{~mol} \mathrm{~L}^{-1}\right)$.

aqueous solution towards various concentrations of $\mathrm{Fe}^{3+}$ were investigated. As shown in Fig. S6a (ESI $\dagger$ ), the UV absorption intensity increased with the increase in $\mathrm{Fe}^{3+}$ concentration due to the absorption of $\mathrm{FeCl}_{3}$. Upon the addition of $\mathrm{Fe}^{3+}$, significant fluorescence quenching could be observed visually in the
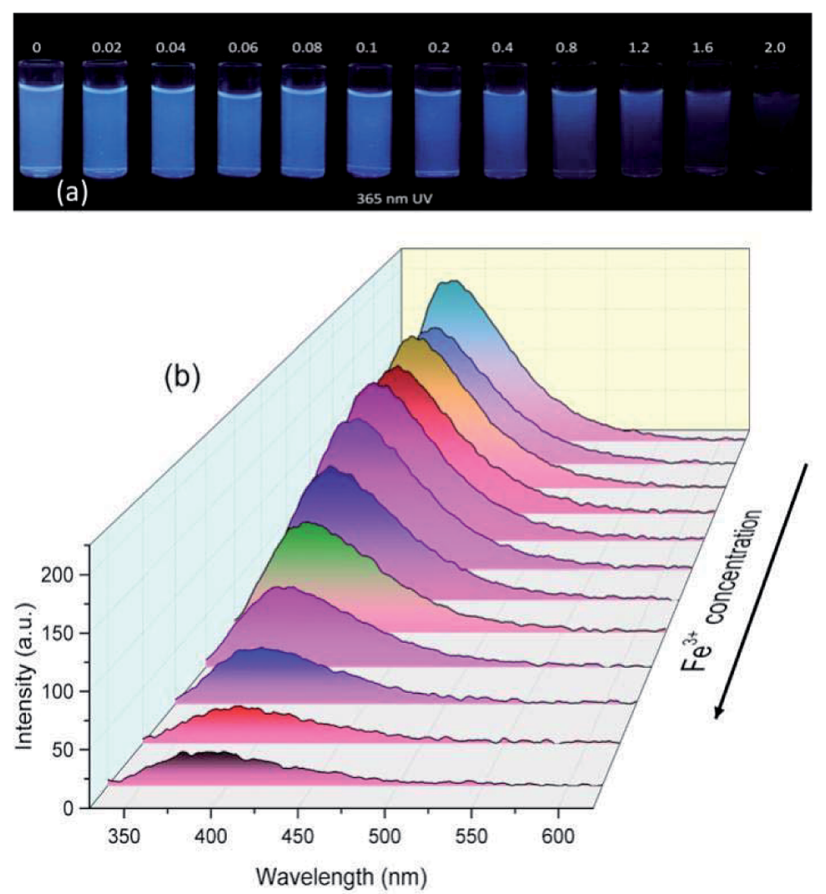

Fig. 5 (a) Photographs taken under $365 \mathrm{~nm}$ UV light and (b) fluorescence spectra of PASAS aqueous solution $\left(5 \mathrm{mg} \mathrm{mL}^{-1}\right)$ on addition of different concentrations of $\mathrm{Fe}^{3+}$. aqueous solution under $365 \mathrm{~nm}$ UV lamp irradiation. Remarkably, the emission intensity (at $380 \mathrm{~nm}$ ) was quenched by about 5.9-fold when the concentration of $\mathrm{Fe}^{3+}$ increased to $2 \times$ $10^{-3} \mathrm{~mol} \mathrm{~L}^{-1}$ (Fig. 5). The fluorescence intensity against the $\mathrm{Fe}^{3+}$ concentration exhibited a good linear relationship $\left(R^{2}=0.9997\right)$ in the range of $0.1 \times 10^{-3}$ to $0.8 \times 10^{-3} \mathrm{~mol} \mathrm{~L}^{-1}$ (Fig. S6b, ESI $\dagger$ ). Based on the above results, it can be confirmed that this polymer sensor could quantitatively detect $\mathrm{Fe}^{3+}$ in aqueous solution. ${ }^{40}$

\section{Conclusions}

In summary, an AIE-active room temperature phosphorescence polymer without heavy-metal atom and halogen was investigated. This polymer is weakly emissive in solution, but could be induced to emit intensely in highly concentrated solutions or in the solid state. The PLQY of the solid sample is $7.57 \%$. Moreover, PASAS also emits RTP under ambient conditions, the phosphorescence emission peak and lifetime at 460 and $525 \mathrm{~nm}$ were $0.24 \mathrm{~ms}$ and $0.77 \mathrm{~ms}$, respectively. Furthermore, the potential application of this polymer as a fluorescence sensor has been demonstrated by using it as a $\mathrm{Fe}^{3+}$ probe. All these advantages make it a very promising material for developing luminescent devices for a large number of applications.

\section{Conflicts of interest}

There are no conflicts to declare.

\section{Acknowledgements}

This work was financially supported by the National Natural Science Foundation of China $(51603050,51863006)$, the Natural Science Foundation of Guangxi (2016GXNSFBA380196), Guangxi University Young and Middle-aged Teachers Basic Ability Promotion Project (KY2016YB316).

\section{Notes and references}

1 Y. Sagara and T. Kato, Nat. Chem., 2009, 1, 605.

2 N. Sang, C. Zhan and D. Cao, J. Mater. Chem. A, 2015, 3, 9296.

3 W. Zhang Yuan and Y. Zhang, J. Polym. Sci., Part A: Polym. Chem., 2017, 55, 560-574.

4 F. Bella, G. Griffini, J.-P. Correa-Baena, G. Saracco, M. Grätzel, A. Hagfeldt, S. Turri and C. Gerbaldi, Science, 2016, 354, 203-206.

5 S. Y. Lee, T. Yasuda, H. Komiyama, J. Lee and C. Adachi, Adv. Mater., 2016, 28, 4019-4024.

6 S. T. Duong and M. Fujiki, Polym. Chem., 2017, 8, 4673-4679.

7 G. D. Gutierrez, I. Coropceanu, M. G. Bawendi and T. M. Swager, Adv. Mater., 2016, 28, 497-501.

8 R. Hu, N. L. Leung and B. Z. Tang, Chem. Soc. Rev., 2014, 43, 4494-4562.

9 J. Mei, N. L. Leung, R. T. Kwok, J. W. Lam and B. Z. Tang, Chem. Rev., 2015, 115, 11718-11940. 
10 J. Luo, Z. Xie, J. W. Lam, L. Cheng, H. Chen, C. Qiu, H. S. Kwok, X. Zhan, Y. Liu and D. Zhu, Chem. Commun., 2001, 1740-1741.

11 Y. Hong, J. W. Lam and B. Z. Tang, Chem. Commun., 2009, 4332-4353.

12 Z. Sheng, B. Guo, D. Hu, S. Xu, W. Wu, W. H. Liew, K. Yao, J. Jiang, C. Liu and H. Zheng, Adv. Mater., 2018, 30, 1870214.

13 M. Chen, R. Chen, Y. Shi, J. Wang, Y. Cheng, Y. Li, X. Gao, Y. Yan, J. Z. Sun and A. Qin, Adv. Funct. Mater., 2018, 28, 1704689.

14 C.-R. Wang, Y.-Y. Gong, W.-Z. Yuan and Y.-M. Zhang, Chin. Chem. Lett., 2016, 27, 1184-1192.

15 S. Mukherjee and P. Thilagar, Chem. Commun., 2015, 51, 10988-11003.

16 C. Li, X. Tang, L. Zhang, C. Li, Z. Liu, Z. Bo, Y. Q. Dong, Y. H. Tian, Y. Dong and B. Z. Tang, Adv. Opt. Mater., 2015, 3, 1184-1190.

17 Q. Zhou, B. Cao, C. Zhu, S. Xu, Y. Gong, W. Z. Yuan and Y. Zhang, Small, 2016, 12, 6586-6592.

18 X. Yang, G. Zhou and W.-Y. Wong, J. Mater. Chem. C, 2014, 2, 1760-1778.

19 C. C. Chen, W. H. Chang, K. Yoshimura, K. Ohya, J. You, J. Gao, Z. Hong and Y. Yang, Adv. Mater., 2014, 26, 56705677.

20 L. Pan, M.-Y. Xu, L.-J. Feng, Q. Chen, Y.-J. He and B.-H. Han, Polym. Chem., 2016, 7, 2299-2307.

21 Z. Chen, K. Y. Zhang, X. Tong, Y. Liu, C. Hu, S. Liu, Q. Yu, Q. Zhao and W. Huang, Adv. Funct. Mater., 2016, 26, 43864396.

22 Q. Zhao, C. Huang and F. Li, Chem. Soc. Rev., 2011, 40, 25082524.

23 G. Marriott, R. M. Clegg, D. J. Arndt-Jovin and T. M. Jovin, Biophys. J., 1991, 60, 1374-1387.
24 S. Cai, H. Shi, D. Tian, H. Ma, Z. Cheng, Q. Wu, M. Gu, L. Huang, Z. An and Q. Peng, Adv. Funct. Mater., 2018, 28, 1705045.

25 S. K. Min, Y. Yu, C. Coburn, A. W. Phillips, K. Chung, A. Shanker, J. Jung, G. Kim, K. Pipe and S. R. Forrest, Nat. Commun., 2015, 6, 8947.

26 B. Xu, H. Wu, J. Chen, Z. Yang, Z. Yang, Y. C. Wu, Y. Zhang, C. Jin, P. Y. Lu and Z. Chi, Chem. Sci., 2017, 8, 1909.

27 S. Hirata, Adv. Opt. Mater., 2017, 5, 1700116.

28 P. O. Darnerud, Environ. Int., 2003, 29, 841-853.

29 B. J. Finlayson-Pitts and J. N. Pitts, Science, 1997, 276, 10451051.

30 A. Poland and J. C. Knutson, Annu. Rev. Pharmacol. Toxicol., 1982, 22, 517-554.

31 R. Rusakowicz and A. C. Testa, J. Phys. Chem., 1968, 72, 26802681.

32 L. Pan, S. Sun, A. Zhang, K. Jiang, L. Zhang, C. Dong, Q. Huang, A. Wu and H. Lin, Adv. Mater., 2015, 27, 77827787.

33 H. Wang, C. Sun, X. Chen, Y. Zhang, V. L. Colvin, Q. Rice, J. Seo, S. Feng, S. Wang and W. Y. William, Nanoscale, 2017, 9, 1909-1915.

34 A. Sharma, T. Gadly, A. Gupta, A. Ballal, S. K. Ghosh and M. Kumbhakar, J. Phys. Chem. Lett., 2016, 7, 3695-3702.

35 Y. Gong, L. Zhao, Q. Peng, D. Fan, W. Z. Yuan, Y. Zhang and B. Z. Tang, Chem. Sci., 2015, 6, 4438-4444.

36 L. Du, G. He, Y. Gong, W. Z. Yuan, S. Wang, C. Yu, Y. Liu and C. Wei, Compos. Commun., 2018, 8, 106-110.

37 X. Dou, Q. Zhou, X. Chen, Y. Tan, X. He, P. Lu, K. Sui, B. Z. Tang, Y. Zhang and W. Z. Yuan, Biomacromolecules, 2018, 19, 2014-2022.

38 J. Liu and Y. Qian, Dyes Pigm., 2017, 136, 782-790.

39 R. Krämer, Angew. Chem., Int. Ed., 1998, 37, 772-773.

40 L. Lan, Q. Niu, Z. Guo, H. Liu and T. Li, Sens. Actuators, B, 2017, 244, 500-508. 